\title{
The Ratio of Management Forms in the Agrarian Economy
}

\author{
Landysh Sitdikova ${ }^{1}$, Farida Mukhametgalieva ${ }^{1}$, Farit Mukhametgaliev ${ }^{1, *}$ and Alina Battalova ${ }^{2}$ \\ ${ }^{1}$ Kazan State Agrarian University, Kazan, 420015, Russia \\ ${ }^{2}$ Kazan (Volga) Federal University, Kazan, 420008, Russia
}

\begin{abstract}
The relevance of the article topic is due to the need to study the features of the existing structure of the rural economy, the ratio of forms of management of the agrarian business in the context of modern external and internal challenges of the socio-economic environment. The purpose of the article is to develop recommendations for improving the efficiency of rural entrepreneurship based on an analysis of the current situation and identifying the features of the development of forms of management of subjects of agricultural business. The article highlights the results of the analysis of the peculiarities of the development of certain forms of management of agricultural production. It has been established that in modern conditions of the implementation of the program for sustainable development of rural areas and import substitution of food products, the diversity of the rural economy is an objective necessity. Each of the forms of management has its own characteristics of functioning and, under certain conditions, is capable of ensuring the efficiency of activities. Half of agricultural products are produced by small forms of farming, which have a strong impact on volume indicators and are characterized by instability of growth depending on demand and price fluctuations in the market. It is proposed to provide the necessary conditions for combining successful economic activities of different organizational and legal forms of management in rural areas: personal subsidiary plots and peasant (farmer) households, cooperative formations, large forms of organization of agricultural business.
\end{abstract}

\section{Introduction}

The experience of the development of world agriculture shows that the agrarian sector of the economy is characterized by a variety of forms of management of subjects of agrarian business, based on personal participation in production processes and in management. At the same time, the efficiency of the agrarian sector of the economy is not at all related to the forms of ownership and the size of production. In order to solve strategic and tactical tasks, the subjects of agricultural business can create various new formations by combining cooperative and integrated enterprises in various forms, reforming the forms of production and economic relations based on the pooling of capital and other production resources. At the modern stage of development of the agro-industrial complex, the objective reality is the joint effective functioning of large highly mechanized, automated, robotic enterprises that produce the bulk of commercial agricultural products, with medium and small businesses that are able to most flexibly respond to the market situation in the food segment. Reforming and transforming production and economic relations in the agricultural business, depending on the prevailing socio-political and production-economic conditions, can be carried out in different directions. Agrarian policy is the most important component of state economic policy. The dynamic socio-economic development of society, the provision of the population of Russia with high-quality food products of domestic production, which determines the well-being of the people, and most importantly, the preservation of stability, sovereignty and independence of the country, fully depend on its implementation $[1,2]$. In this regard, studies aimed at analyzing the existing state of organization of the activities of agricultural business entities - agricultural organizations, medium and small forms of farming, personal subsidiary plots and identifying reserves for increasing the efficiency of the rural economy acquire great relevance.

\section{Materials and Methods}

The theoretical and methodological basis of the research is based on the use of the possibility of interaction and complementarity of the fundamental provisions and concepts of economic theory. The theoretical and methodological basis was also the works of foreign and domestic agricultural economists on the topic under study, the regulatory and legislative acts of the Russian Federation on the regulation of agri-food policy, materials of international and all-Russian scientific and practical conferences on the development of agriculture. The general methodological basis of the research is the system analysis. The extensive material and the variety of their content have made it necessary to use various approaches, methods and techniques for scientific

\footnotetext{
Corresponding author: fem59@mail.ru
} 
research of socio-economic processes, such as constructive, deterministic, retrospective, dynamic, statistical, within the framework of system analysis.

\section{Results}

The decisions taken to carry out radical political and economic reforms in the early 90 s of the last century paved the way for distortions and fundamental changes in agricultural policy, and served as the beginning of the collapse of the country and the agro-industrial complex. According to the law of the dialectic of the transition period, it was enough to carry out evolutionary measures and adjust individual elements of the organizational and economic mechanism of the functioning of the current management system of organizational forms and models of subjects of agrarian formations. As a result of the voluntaristic decisions made by the authorities of the country, unjustified political approaches, structural transformations were carried out, the results of which subsequently led to the destruction of the systemic nature of the agrarian sector of the economy and a landslide decline in production. Statistical indicators show that "in 1997, compared to 1990, grain production decreased from 116.7 million to 88.5 million tons. meat of all types in slaughter weight - from 10.1 to 5.3 million tons; milk - from 55.1 to 34.1 million tons. In general, the production of gross output in comparable prices decreased by 36.1 percent" [3]. This trend continued at the beginning of the 2000s. Only with the adoption of the Federal Law "On the Development of Agriculture" dated December 29, 2006 and the State Program for the
Development of Agriculture and Regulation of Agricultural Products, Raw Materials and Food Markets for 2013-2020, there has been an increase in agricultural production. However, the pace leaves much to be desired: its volume in 2019 in comparable prices amounted to only $97.9 \%$ of the 1990 level [4]. At the same time, it should be noted that not all normative acts adopted over the years of reforms were destructive, many of them played a positive role, but did not provide for a systematic solution to the problems of comprehensive development of the rural economy and did not form the institutional base of growth drivers.

In the agriculture of Russia and in its regions, a variety of forms of ownership and forms of management has been formed, in other words, a multi-structured economy. At present, agricultural production in the country is carried out by agricultural organizations of various organizational and legal forms, personal subsidiary plots and peasant farms. At the same time, equality and equality of all types of management and property are legally enshrined. Each of the forms of farming has features of organization and functioning and, under certain conditions, is capable of ensuring production efficiency [5, 6]. An agricultural producer can freely choose the form of farming, and the result of his choice and the best combination of various and equal forms of farming in multi-structure agriculture should be determined depending on the level of production efficiency in each of them. According to Rosstat, as of 01.01.2020, the structure of agricultural organizations by type of management was as follows (Fig. 1).

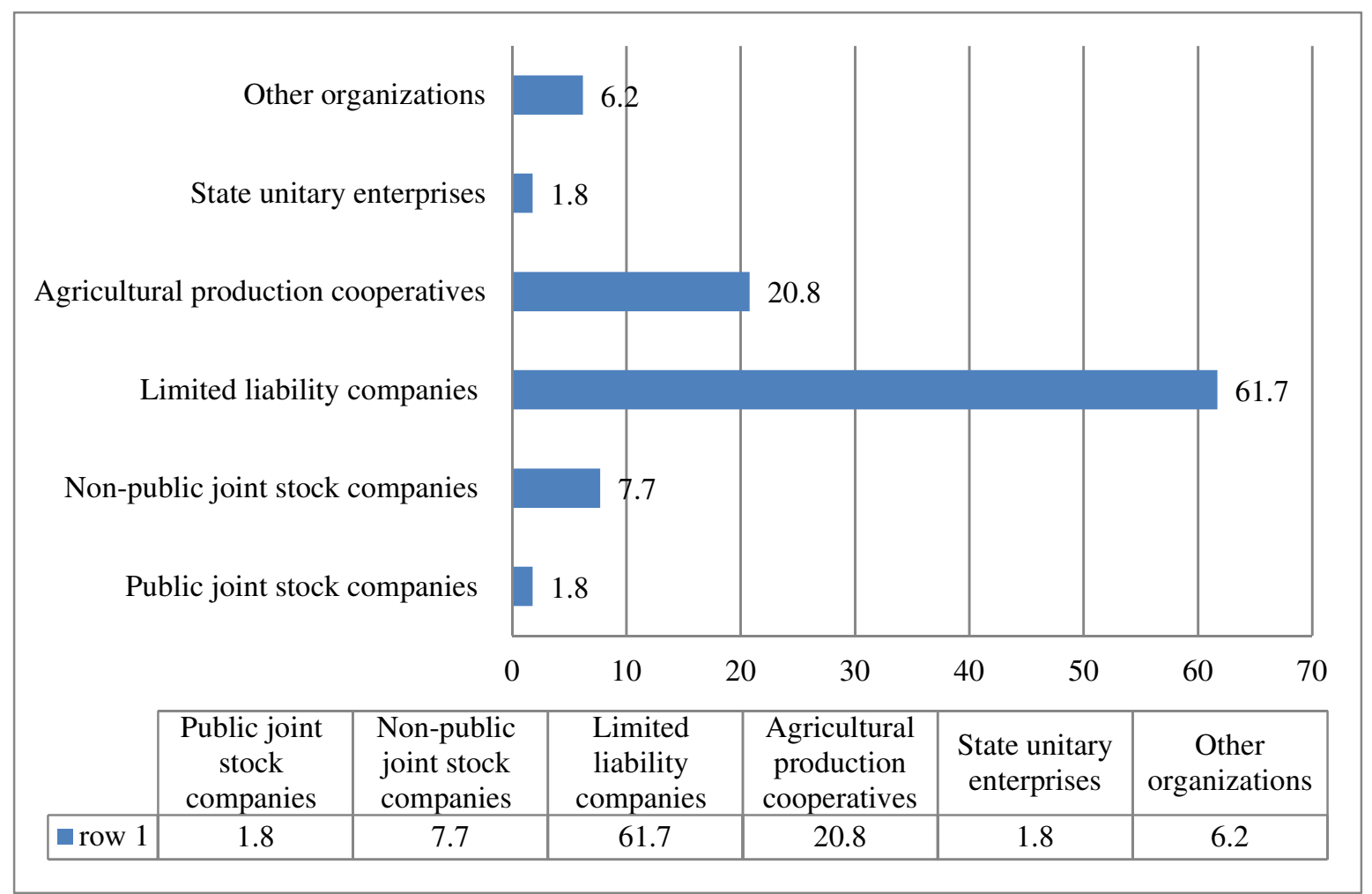

Fig. 1. The structure of agricultural organizations by forms of management, \% (as of January 1, 2020) [4] 
The largest share in the total number of agricultural organizations belongs to limited liability companies, as of 01.01 .2020 it amounted to $61.7 \%$. Agricultural production cooperatives are inferior to this form of management in quantitative terms: their share is $20.8 \%$. The share of joint stock public joint stock companies is $1.8 \%$ and that of non-public joint stock companies is $7.7 \%$. An insignificant share of state unitary enterprises remains $(1.8 \%)$. The share of agricultural organizations of other forms of management is $6.2 \%$ of their total number.

The established structure is not permanent. The agrarian business, as a dynamic sphere, is constantly in motion, its numerical and qualitative composition, the ratio of forms of management are changing. Moreover, depending on the variety of conditions of functioning and location in different regions of the country, they have different meanings. According to Rosstat, in 2004 in Russia the share of agricultural production cooperatives (APC) accounted for $57 \%$ of the total number of agricultural organizations in the country (AO), the share of joint-stock companies was $17.8 \%$, that of limited liability companies was only $14.2 \%$. Thus, we can state a noticeable decrease in the share of agricultural production cooperatives in the total number of agricultural enterprises, a slight decrease in the share of joint-stock companies and a significant increase in the share of limited liability companies [7, 8].

Such a sharp decline in the share of APXs is due to the following reasons. The initial stage of reforms was aimed at the reorganization and de-collectivization of agricultural enterprises, which led to a decrease in the popularity of collective forms of management, such as agricultural production cooperatives. In addition, this was facilitated by the adopted bankruptcy law, which provided for a provision on the inadmissibility of the withdrawal of fixed assets of production in the case of the bankruptcy of agricultural production cooperatives. This situation contributed to limiting their access to credit resources of banks and other borrowed funds. The reduction in the role of agricultural production cooperatives occurred due to objectively existing difficulties in accessing financial resources for this category of farms. Their share in the accounts payable of all agricultural production cooperatives has fallen 6 times over 10 years. This situation cannot be considered normal, because the cooperation of medium and small forms of management is a necessary condition for the normal functioning of this most important category of agricultural organizations. But, agriculture, as an industry requiring the use of collective forms of management and organization of production, contributed to the adoption of decisions by the management bodies of the agro-industrial complex to restore cooperative formations in rural areas. In economically developed countries, this figure reaches 70 percent [9].

The number of personal subsidiary plots (PSP) and peasant (farm) holdings (PFHs) also changes over time. In the early $90 \mathrm{~s}$, there was a noticeable increase in the number of PFHs. According to Rosstat, the largest number of them was reached in 1996 (280.1 thousand farms). According to the results of the All-Russian agricultural census of 2006 in the Russian Federation, as of July 1, 2006, the number of PFHs amounted to 253.1 thousand farms. And according to the data of the AllRussian Agricultural Census of 2016 in the Russian Federation, as of July 1, 2016, their number decreased to 136.7 thousand [3]. The decrease in the number of PFHs can be explained, first of all, by the insufficient level of preparedness of managers and members of farms to solve organizational and technological issues of the functioning of small forms of activity, insufficient turnover of funds necessary to provide a modern material and technical base, purchase and use of modern innovative techniques and technologies. Also, as of 01.07.2006, there were 22.8 million private household plots in Russia. According to the data of the All-Russian Agricultural Census of 2016 in the Russian Federation, as of July 1, 2016, the number of private household plots amounted to 17.5 million. [3, 4] The number and development trends of private household plots are determined by the socio-economic situation in rural areas. In the context of the crisis, stagnation of production and financial activities of large farms, deterioration in the quality of life of the rural population, high unemployment and higher energy prices, private household plots play an important role in solving the problem of providing the population with food of their own production. In addition, in some periods for many rural residents, private household plots serve as a means of self-sufficiency.

In modern conditions of implementation of the program for sustainable development of rural areas and import substitution of food products, the diversity of the rural economy is an objective necessity. It is dictated primarily by the specifics of agricultural production and the variety of technological operations performed and manufactured products. At the same time, the formation and effective functioning of the subjects of a mixed economy is largely determined by local regional features of the agricultural production system, such as: climatic, political, socio-economic and demographic. Due to the fact that in different regions there are different conditions for agricultural production in certain areas of agriculture, this is the reason that the multi-structured environment in agriculture in different regions of the country is different [10]. Thus, regional features are the main determining factors in the formation and dynamics of a mixed economic environment in rural areas of the country's regions. Organizational and legal forms, characteristics of manufactured products, local traditions in relation to individual branches of production, imposed on the specifics of the region, the prerequisites for organizing activities in different conditions, can bring different production results. In this regard, the current state of agriculture in Russia requires a search for ways to improve the efficiency of domestic agricultural production. The executive authorities in the course of making managerial decisions should recognize the formation and effective functioning of a multi-structured system of farming on the basis of achieving certain optimal changes in the composition and structure of various forms of agrarian business entities as one of the priority areas for the development of the rural economy 
[11-13]. At the same time, in addition to the specific features of the forms of management, it is necessary to take into account the programs of long-term strategic development of the regions and the implemented regional programs for achieving high results in the rural economy.

As a result of the implementation of the agricultural policy, taking into account the above-mentioned features in the rural economy in recent years, stable results of the growth of production indicators have been achieved, as evidenced by the indicators of the index of the physical volume of agricultural production by categories of farms (Table 1).

Table 1. Indices of the physical volume of agricultural products by categories of farms (in comparable prices, $\%$ to the previous year) [3]

\begin{tabular}{|c|c|c|c|c|}
\hline \multirow{2}{*}{ Farm category } & \multicolumn{4}{|c|}{ Years } \\
\cline { 2 - 5 } & $\mathbf{2 0 1 6}$ & $\mathbf{2 0 1 7}$ & $\mathbf{2 0 1 8}$ & $\mathbf{2 0 1 9}$ \\
\hline Farms of all categories & 104.8 & 102.9 & 99.8 & 104.0 \\
\hline Including: & & & & \\
\hline Agricultural organizations & 108.0 & 105.8 & 100.0 & 105.8 \\
\hline Peasant (farm) households & 113.5 & 110.1 & 97.7 & 110.2 \\
\hline Households of the population & 97.0 & 95.7 & 100.2 & 98.1 \\
\hline
\end{tabular}

The table shows that for all categories of farms, the progressive development of agricultural production is ensured, an increase in production in the industry as a whole is observed annually. Agricultural organizations, as representatives of large forms of agrarian business, are distinguished by stable indicators, peasant (farm) households are developing at a faster pace, as the most mobile and quickly responding to the market situation part of the rural economy. Personal subsidiary plots of the population are experiencing a slight annual decrease, most likely due to a decrease in the number and working-age population of rural areas. According to the volume of production, the structure of a mixed economy in agriculture has developed (Table 2).

Table 2. Structure of agricultural products by categories of farms, \% (in actual prices) [4]

\begin{tabular}{|c|c|c|c|c|}
\hline \multirow{2}{*}{ Farm category } & \multicolumn{4}{|c|}{ Years } \\
\cline { 2 - 5 } & $\mathbf{2 0 1 6}$ & $\mathbf{2 0 1 7}$ & $\mathbf{2 0 1 8}$ & $\mathbf{2 0 1 9}$ \\
\hline Farms of all categories & 100 & 100 & 100 & 100 \\
\hline Including: & & & & \\
\hline Agricultural organizations & 55.1 & 55.2 & 56.5 & 58.2 \\
\hline Peasant (farm) households & 12.4 & 12.4 & 12.5 & 13.6 \\
\hline $\begin{array}{c}\text { Households of the } \\
\text { population }\end{array}$ & 32.5 & 32.4 & 31.0 & 28.2 \\
\hline
\end{tabular}

In Russian agriculture, the main commodity producers are agricultural organizations, which provide $58.2 \%$ of the volume of production in the agrarian sector of the economy; over the past four years, it has increased its share by $3.1 \%$. Peasant (farming) households retain their niche with a slight increase in the structure of agricultural production by $1.2 \%$ in 20162019. A comparative analysis of the dynamics of volume indicators indicates a predominant growth in production over the past four years in agricultural organizations by $22.0 \%$ and peasant (farm) households by $26.7 \%$. With an approximately uniform growth and development of crop and livestock industries, the growth in these categories of farms led to a decrease in the share of personal subsidiary plots of the population by $4.3 \%$, which left their production volume at the same level (Table 3).

Table 3. Agricultural products by categories of farms (in actual prices; billion rubles) [3]

\begin{tabular}{|c|c|c|c|c|c|}
\hline \multirow[t]{2}{*}{ Types of products } & \multicolumn{4}{|c|}{ Years } & \multirow{2}{*}{\begin{tabular}{|c}
2019 in \\
$\%$ to \\
2016
\end{tabular}} \\
\hline & 2016 & 2017 & 2018 & 2019 & \\
\hline \multicolumn{5}{|c|}{ Farms of all categories } & \\
\hline Agricultural products & 5112.3 & 5109.5 & 5348.8 & 5907.9 & 115.6 \\
\hline \multicolumn{6}{|l|}{ including: } \\
\hline crop production & 2710.3 & 2599.7 & 2756.1 & 3160.0 & 116.6 \\
\hline animal h & 2402.0 & 2509.8 & 2592.7 & 2747.9 & 114.4 \\
\hline \multicolumn{5}{|c|}{ Agricultural organizations } & \\
\hline Agricultural products & 2818.4 & 2818.5 & 3022.1 & 3438.5 & 122.0 \\
\hline \multicolumn{6}{|l|}{ including: } \\
\hline crop production & 1428.4 & 1336.3 & 1438.8 & 1730.0 & 121.1 \\
\hline animal 1 & 1390.0 & 1482.2 & 1583.3 & 1708.5 & 122.9 \\
\hline \multicolumn{5}{|c|}{ Households of population } & \\
\hline Agricultural products & 1659.2 & 1655.4 & 1656.7 & 1665.7 & 100.4 \\
\hline \multicolumn{6}{|l|}{ including: } \\
\hline crop production & 768.9 & 764.2 & 787.1 & 780.0 & 101.4 \\
\hline animal husbandry & 890.3 & 891.2 & 869.6 & 885.7 & 99.5 \\
\hline \multicolumn{5}{|c|}{ Peasant (farm) households } & \\
\hline Agricultural products & 634.7 & 635.6 & 670.0 & 803.7 & 126.6 \\
\hline \multicolumn{6}{|l|}{ including: } \\
\hline crop production & 513.0 & 499.2 & 530.2 & 650.0 & 126.7 \\
\hline animal husbandry & 121.7 & 136.4 & 139.8 & 153.7 & 126.3 \\
\hline
\end{tabular}

The reason for this is seen mainly in the possibilities of mechanization, automation and digitalization of the execution of technological processes and, due to this, an increase in the productivity and attractiveness of rural labor in different categories of farms in terms of the scale of production and the size of production facilities. The advantages of large forms of agricultural business, possessing large-scale financial, material and human resources, are indisputable here.

\section{Conclusion}

In general, it can be stated that in the conditions of today's realities in the agrarian sphere of the country's economy, the necessary conditions have been created for combining successful economic activities of various organizational and legal forms of management in rural areas: personal subsidiary plots and peasant (farm) households, cooperative formations, large forms of organization of the agrarian business. Along with this, to ensure their effective activity, it is necessary to present the possibility of choosing a segment of the agrarian economy, the type of products produced and the branch of agricultural production, taking into account natural, economic, demographic and other regional conditions. Today, a state agrarian policy is needed, on the one hand, ensuring equal conditions for agricultural producers of various forms of management, on the other hand, taking into account the multi-structured 
differences in agriculture. In the conditions of today's realities, agrarian-political activity is aimed at influencing the preparation and implementation of state programs and private economic plans so that the result of the activities of each of the individual enterprises becomes the desired general economic result in the context of import substitution caused by the sanctions of Western European countries and the USA.

\section{References}

1. F.N. Mukhametgaliev, F.N. Avkhadiev, The Economic Mechanism of the Functioning of Subdivisions of Agricultural Enterprises, Monograph (KSAA, Kazan, 2000), 190 p.

2. D.I. Fayzrakhmanov, Current state and problems of agricultural development in the context of Russia's membership in the WTO, Bull. of Kazan State Agrar. Univer., 2, 58-64 (2013)

3. Federal State Statistics Service of the Russian Federation, Retrieved from: http www.gks.ru

4. Russia in Figures, Brief Statistical Collection (Rosstat, Moscow, 2019), 549 p.

5. L.V. Mikhailova, Methodological features of planning the development of small businesses in agriculture, Competitiv. in the global world: econ., sci., technol., 7 (part 4), 100-103 (2017)

6. I.G. Gainutdinov, D.I. Fayzrakhmanov, Development of the social infrastructure of the village and its impact on the economic indicators of agricultural production, Bull. of the Kazan State Agrar. Univ., 3, 39-55 (2015)

7. D.F. Khafizov, Features of the current stage of development of a mixed economy, Bull. of Kazan State Agrar. Univ., 3, 157-161 (2018)

8. F. Mukhametgaliev, L. Sitdikova, M. Khismatullin et al., Prospects of agricultural business in the Republic of Tatarstan, BIO Web of Conf., 17 (2020), Retrieved from: https:doi.org10.1051bioconf20201700059

9. D.F. Khafizov, Issues of development of small forms of management and cooperation in rural areas, Bull. of Kazan State Agrar. Univ., 1, 138-144 (2019)

10. A.R. Battalova, R.S. Tukhvatullin, F.N. Mukhametgaliev et al., Priority areas of development of agricultural entrepreneurship in the regions of the Russian Federation, Int. J. on Emerg. Technol., 10(2), 133-136 (2019)

11. D.I. Fayzrakhmanov, O.V. Kirillova, Features of state support for the agricultural sector of the Russian economy and its role in supporting the country's food security, Bull. of Kazan State Agrar. Univ., 2, 49-53 (2015)

12. L.R. Bilalova, Strategic enterprise management in the agro-industrial complex, Vector of econ., 4(22), 67 (2018)

13. R.R. Islamiev, Agrarian Sector of the Republic of Tatarstan, Agricult. Econ. of Russ., 5, 32 (2001) 